\title{
Geographic Variability of Active Ingredients in Spice as an Indicator of Mechanisms of Distribu- tion and Manufacture Within Alaska
}

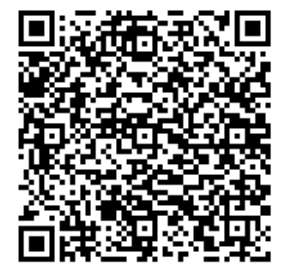

\author{
Dakota W. Emery ${ }^{1}$, Christopher R. Iceman ${ }^{1,2}$, Sarah M. Hayes ${ }^{1 *}$
}

Designer drugs, like Spice, are synthetic psychoactive analogs of illegal substances with understudied health effects since they have traditionally been sold in packages labeled "not for human consumption" and the molecular structures can be specifically altered to circumvent legislation. Recent legislation has focused on regulating packaging and has reduced, but not eliminated, the distribution of Spice in Alaska. Legally obtained Spice samples from three geographic regions in Alaska were analyzed using liquid injection gas chromatography-mass spectrometry (GC-MS). Most (70\%) of the samples contained illegal cannabinoids that have been regulated by the Drug Enforcement Agency and 47\% contained multiple active ingredients. We hypothesized that the heterogeneity of the active ingredients between brands and across regions could be used to indicate small- or larger-scale manufacturing, and the results indicate multiple manufacturing scales. Evidence for small-scale manufacturing included inconsistent packaging, several of which contained similar active ingredient profiles in different brands purchased from a single store. Evidence for large-scale production was also found with some brands having consistent active ingredient profiles across regions. This study provides preliminary data for the geographic variability of active ingredients in Spice as an indicator of mechanisms of manufacture and distribution to inform legislators and law enforcement and help prioritizing resource allocation in an effort to quell Spice use in Alaska.

\section{INTRODUCTION}

Spice is often, but inappropriately, called synthetic marijuana and is produced in laboratory with the goal of mimicking or enhancing the effects of the natural cannabinoids, like the naturally occurring tetrahydrocannabinol (THC) in cannabis. Spice consists of a mixture of ordinary herbs, such as red clover (Ogata, Uchiyama, Kikura-Hanajiri, \& Goda, 2012) sprayed with synthetic cannabinoid compounds, which can be smoked to produce psychoactive effects reported to be similar to those of cannabis (Hudson \& Ramsey, 2011). As detailed in a Congressional Research Service Report, which provides background on the legal history and effects of synthetic drugs, Spice's acute effects are often more harmful than its natural counterpart with unknown long-term effects (Sacco \& Finklea, 2013).

\section{${ }^{1}$ Department of Chemistry and Biochemistry, University of Alaska Fairbanks, 505 S. Chandalar Dr, Fairbanks AK 99775 \\ ${ }^{2}$ Valparaiso University, 1700 Chapel Dr, Valparaiso IN 46383}

*To whom correspondence should be addressed: shayes@usgs.gov

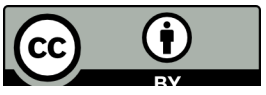

Except where otherwise noted, this work is licensed under https://creativecommons.org/licenses/by/4.0

doi:10.22186/jyi.34.4.7-16
The effects of Spice include reduced blood pressure and a feeling of relaxation, which are characteristic of marijuana. However, there are other negative effects, including nausea, altered mental status, drug-induced psychosis, agitation, elevated blood pressure, tachycardia, seizures, acute organ function impairment and death (Castellanos \& Gralnik, 2016; Centers for Disease Control and Prevention [CDC], 2012; CDC, 2013a; CDC, 2013b; Kasper et al., 2015; Sacco \& Finklea, 2013). The effects observed after Spice consumption are highly variable, partly because packages of Spice can contain one or more synthetic cannabinoids that can vary in composition and potentially have synergistic effects (Springer et al., 2016). These drugs, since ostensibly not intended for human consumption, are not controlled in the same manner as legitimate pharmaceuticals, and thus do not undergo the same extensive health and safety testing prior to sale.

The popularity of smoking herbal blends, generically called Spice after the name of the most popular brand (other common brands of herbal blends include K2, Potpourri, and Yucatan Fire), has increased since synthetic cannabinoids were first detected within herbal blends in 2008 (Auwärter et al., 2009). In 2015, a $330 \%$ increase in Spice-related calls to U.S. Poison Control Centers was observed between January and April (Law, Schier, Martin, Chang, \& Wolkin, 2015). Later in the same year, between July and September 2015, a substantial increase in synthetic cannabinoidrelated ambulance transports (ranging from $<1 \%$ to up to $36.9 \%$ of daily transports) was observed in Anchorage, AK (Springer et al., 2016). This outbreak has sparked efforts to curb the use of Spice 
in Alaska.

Implementing legislation to restrict the sale and use of Spice has been complicated by the historical legal process, which has focused on targeting specific synthetic molecules or natural materials. Synthetic designer drugs are amenable to slight modifications to the chemical structure, which creates a new compound that still produces psychoactive effects but is not affected by legislation, effectively circumventing legal restrictions (Carroll et al., 2012; Sacco \& Finklea, 2013). When a synthetic cannabinoid is scheduled, licensed shops are required to stop selling the product, but due to a lack of routine scrutiny of Spice products, manufacturers may not actually be changing the makeup of Spice to exclude the controlled substances. Further complicating regulation, Spice has traditionally been sold in packages labeled "not for human consumption" (Hudson \& Ramsey, 2011). This has forced recent legislation to focus on regulating packaging, which has successfully reduced the distribution of Spice through legal avenues by forcing smoke shops to stop selling Spice until the packages meet regulations for products intended for human consumption or pay a $\$ 500$ citation for each package of Spice (AK Stat $\S 17.21 .010,2014$ ). However, this has not eradicated the widespread presence and use of Spice within the state (Andrews, 2015; Springer et al., 2016).

There is ambiguity in how Spice is being manufactured, as either it can be purchased prepackaged from larger-scale facilities, or the raw chemicals and herbal matter can be purchased for regional, local, or in-shop herb treatment prior to distribution. This question is of particular interest in Alaska due to unique challenges related to distribution of goods, which may lead to distinctive production patterns for Spice. Alaska is geographically large, over twice the land area of Texas, with an extremely limited road system (only 16,301 miles of roads) and substantial transport of goods via air and water routes (Alaska Department of Transportation, 2012). Thus, law enforcement resources are challenged by the large and remote geographic area, which limits the capacity for detecting drug traffickers and clandestine labs (Booth, Wooller, Howe, \& Haubenstock, 2010). Previous similar work on marijuana used stable isotopes to identify the source of marijuana plants (local grow houses, regional growers or interstate transport), and helped law enforcement agencies in targeting efforts to reduce marijuana use in the state of Alaska (Booth et al., 2010). Similarly, the goal of this study is to use active ingredient profiles to examine the Spice production methods for informed law enforcement efforts.

This project seeks to map the geographic variability of the ingredients in Spice obtained legally from three locations in Alaska, which were analyzed to identify the presence of illegal substances and to examine the methods of Spice manufacture and distribution in Alaska. As illustrated in Figure 1, we hypothesize that homogeneity in either the active ingredient or herbal material within multiple brands of Spice, a single shop or geographic region points to local Spice production, while homogeneity within a brand across regions or heterogeneity between brands points to a remote distributor. For example, geographic variability within a single brand purchased from several locations points to local distributors and

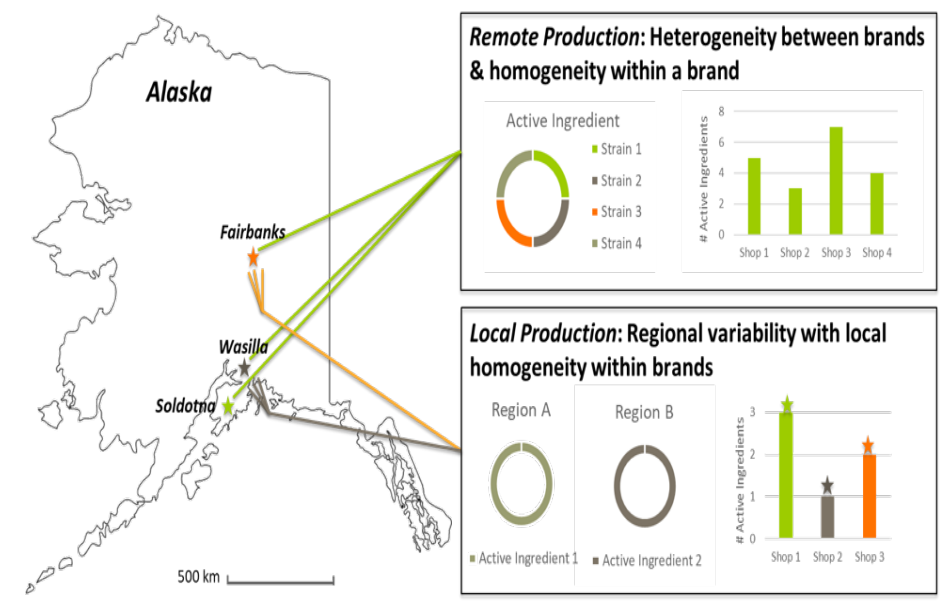

Figure 1. Hypothesis of how relationships between active ingredients may relate to mechanisms of Spice production. Samples for this study were collected in Fairbanks, Wasilla and Soldotna, shown on map (http://www.worldatlas.com/webimage/countrys/namerica/usstates/outline/ak.gif). Via ground transportation, Soldotna is $304 \mathrm{~km}$ from Wasilla and $812 \mathrm{~km}$ from Fairbanks; Wasilla is located $508 \mathrm{~km}$ from Fairbanks.

homogeneity within a shop indicates in-house production. These results have the potential to aid law enforcement agencies in targeting their efforts to reduce the production, distribution, and use of Spice in Alaska.

\section{MATERIALS AND METHODS}

\section{Sample Collection and Packaging Observations}

A total of 25 Spice samples, pictured in Figure 2, were purchased from licensed smoke shops in Soldotna (12 samples), Wasilla (11 samples) and Fairbanks (2 samples), details in Table 1. The University of Alaska Fairbanks (UAF) Police Department provided a safe sample storage as well as transport and disposal services. Upon arrival in the laboratory, samples underwent close visual inspection of the packaging to identify any inconsistencies in the heat seal quality, labeling, printing quality, presence of foreign material underneath stickers and photographs were taken using an iPhone 5s rear camera (8MP, f/2.2, 29mm, autofocus).

Sample Preparation

Samples of Spice were prepared and analyzed in triplicate in accordance with published methods (Hudson \& Ramsey, 2011). Briefly, the samples were homogenized with a coffee grinder for 30 s to reduce particle size and to mix the sample. Triplicate subsamples of approximately $50 \mathrm{mg}$ of the sample were transferred into a $4 \mathrm{ml}$ glass vial and $2 \mathrm{ml}$ of high performance liquid chromatographygrade methanol (EMD) was added. This mixture was sonicated for $10 \mathrm{~min}$ and then allowed to settle for another $10 \mathrm{~min}$. One milliliter of the supernatant was transferred by pipette to a $2 \mathrm{ml}$ glass vial for storage at room temperature. These methanol extracts were created and analyzed in triplicate by GC-MS within two days as previous studies have shown that after 2 days, the synthetic cannabinoids in methanol extracts can adsorb to the inner surface of the GC- 


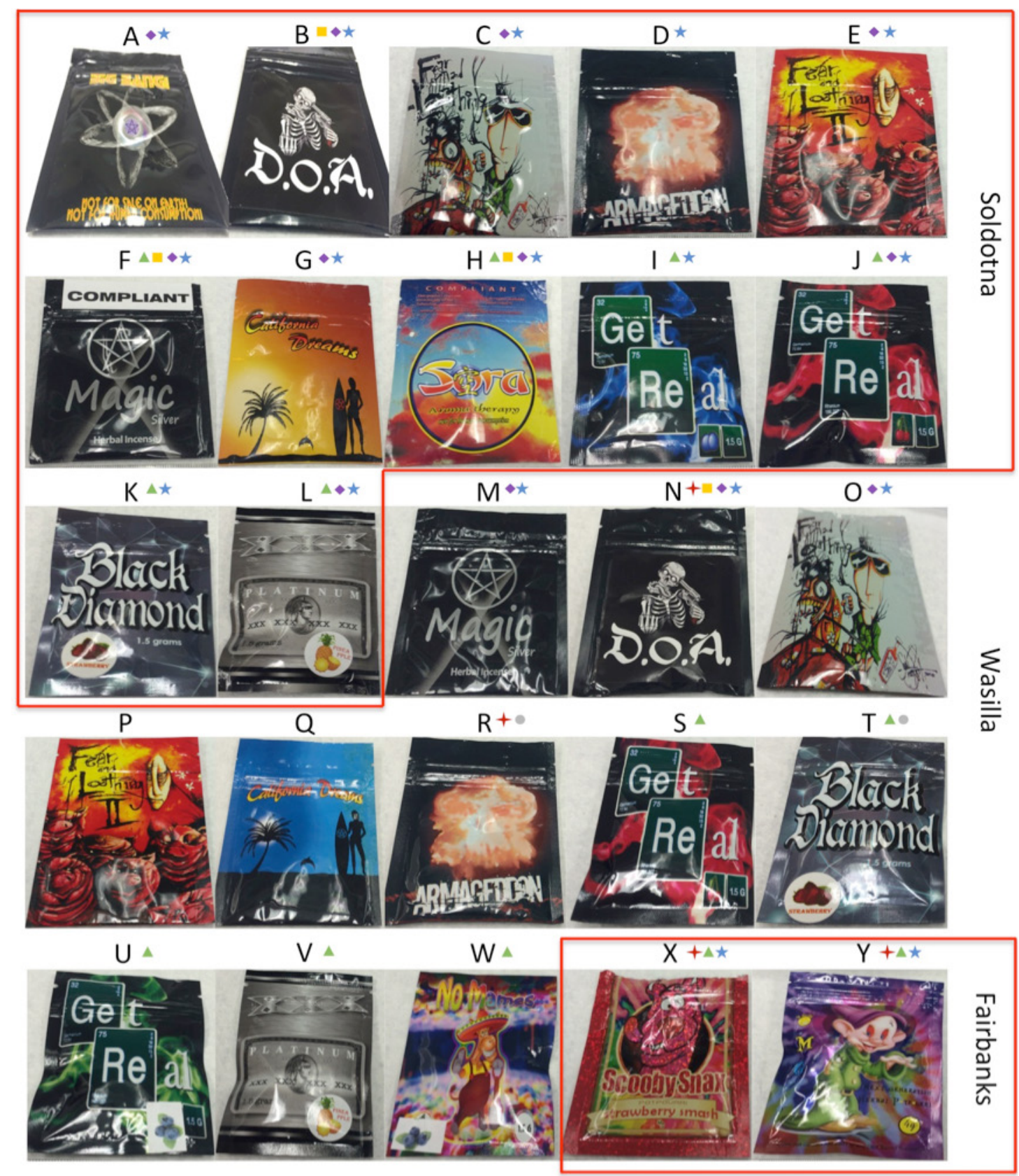

Figure 2. Photographs of 25 packages of Spice samples acquired from three smoke shops throughout Alaska. Samples A-L were obtained from Soldotna, M-W were obtained from Wasilla, and samples X and Y were obtained from Fairbanks. Legend: + Unsealed package, $\boldsymbol{M}$ Labelled compliant, Blurry graphics, Sticker labels, C Contains regulated cannabinoids, * Tested with GC-MS.

MS glass vials (Köhling, 2011). The triplicate analyses resulted in very similar GC-MS spectra and fragmentation patterns. The implementation of AK Stat $\S 17.21 .010$ prevented the analysis of all Spice samples as they were surrendered to the police when legislation took effect.

Gas Chromatography-Mass Spectrometry Analysis

Prior to Gas Chromatography-Mass Spectrometry (GC-MS) analysis, $100 \mu 1$ of the methanol extract was transferred into a GC-MS vial and evaporated to dryness by leaving it uncapped in a fume hood overnight for approximately $15 \mathrm{hr}$. The sample was then reconstituted in $30 \mu 1$ of spectrophotometric grade toluene (Alpha Aesar, Ward Hill, MA) followed by $20 \mu 1$ of N-methyl-Ntrimethylsilytrifluoroacetamide (Sigma-Aldrich, St. Louis, MO; lot $51 \mathrm{k} 1524)$ prior to analysis. The samples were analyzed using an Agilent 7890A GC system connected to an Agilent 5975C Inert EI/CI MSD (Santa Clara, CA) using electron ionization and a 


\begin{tabular}{|c|c|c|c|c|c|c|c|}
\hline Sample ID & Brand & $\begin{array}{l}\text { Location of } \\
\text { purchase }\end{array}$ & Package size & Sealed? & $\begin{array}{l}\text { Analyzed by } \\
\text { GC-MS? }\end{array}$ & $\begin{array}{l}\text { Active ingredients (percent database } \\
\text { match) }\end{array}$ & Observations \\
\hline A & Big Bang & Soldotna & $\mathrm{L}$ & $\mathrm{S}$ & $\mathrm{Y}$ & $\begin{array}{l}\text { JWH-081 (98.3\%); JWH-018 } \\
\text { (98.4\%); JWH-073 (71.2\%); RCS-04 } \\
(97.2 \%)\end{array}$ & \\
\hline $\mathrm{B}$ & D.O.A. & Soldotna & $\mathrm{L}$ & $\mathrm{S}$ & $\mathrm{Y}$ & $\begin{array}{l}\text { JWH-081 (98.3\%); JWH-019 }(98.0 \%) \\
\text { JWH-018 (98.4\%); JWH-073 (95.0\%) } \\
\text { RCS-04 (97.6\%); JWH-250 (88.4\%) } \\
\text { JWH-203 (88.2\%) }\end{array}$ & $\begin{array}{l}\text { Stickers front and } \\
\text { back labels }\end{array}$ \\
\hline $\mathrm{C}$ & $\begin{array}{l}\text { Fear and } \\
\text { Loathing }\end{array}$ & Soldotna & $\mathrm{L}$ & $\mathrm{S}$ & $\mathrm{Y}$ & JWH-018 (51.8\%) & \\
\hline $\mathrm{D}$ & Armageddon & Soldotna & $\mathrm{L}$ & $\mathrm{S}$ & Y & N/A & \\
\hline $\mathrm{E}$ & $\begin{array}{l}\text { Fear and } \\
\text { Loathing II }\end{array}$ & Soldotna & $\mathrm{L}$ & $\mathrm{S}$ & $\mathrm{Y}$ & $\begin{array}{l}\text { JWH-081 (98.4\%); JWH-019 (98.2\%) } \\
\text { JWH-018 (98.4\%); JWH-073 (96.3\%) } \\
\text { RCS-04 (97.6\%); JWH-250 (92.6\%) } \\
\text { JWH-203 (74.1\%) }\end{array}$ & $\begin{array}{l}\text { "1g" written on the } \\
\text { back with a marker. }\end{array}$ \\
\hline $\mathrm{F}$ & Magic Silver & Soldotna & $\mathrm{L}$ & $\mathrm{S}$ & Y & $\begin{array}{l}\text { JWH-018 (94.8\%); JWH-073 (46.1\%) } \\
\text { JWH-250 (57.9\%) }\end{array}$ & $\begin{array}{l}\text { Compliant sticker } \\
\text { over seal }\end{array}$ \\
\hline G & $\begin{array}{l}\text { California } \\
\text { Dreams } \\
\text { Orange color }\end{array}$ & Soldotna & $\mathrm{L}$ & $\mathrm{S}$ & Y & $\begin{array}{l}\text { JWH-081 (98.2\%); JWH-019 (96.9\%) } \\
\text { JWH-018 (98.4\%); JWH-073 (94.1\%) } \\
\text { JWH-251 (43.1\%); JWH-203 (82.5\%) } \\
\text { RCS-04 (97.2\%); JWH-250 (86.3\%) }\end{array}$ & $\begin{array}{l}\text { "3" written over the } \\
\text { printed the number } 1 \\
\text { in " } 1 \text { " on the back } \\
\text { in marker. }\end{array}$ \\
\hline $\mathrm{H}$ & Sora & Soldotna & $\mathrm{L}$ & $\mathrm{S}$ & $\mathrm{Y}$ & JWH-398 (96.8\%); JWH-018 (98.5\%) & $\begin{array}{l}\text { Compliant sticker } \\
\text { over seal }\end{array}$ \\
\hline I & $\begin{array}{l}\text { Get Real } \\
\text { Blue color }\end{array}$ & Soldotna & $\mathrm{S}$ & $\mathrm{S}$ & $\mathrm{Y}$ & N/A & $\begin{array}{l}\text { Compliant label- } \\
\text { package back }\end{array}$ \\
\hline $\mathrm{J}$ & $\begin{array}{l}\text { Get Real } \\
\text { Red color }\end{array}$ & Soldotna & $\mathrm{S}$ & $\mathrm{S}$ & $\mathrm{Y}$ & JWH-018 (29.6\%) & $\begin{array}{l}\text { Compliant label- } \\
\text { package back }\end{array}$ \\
\hline $\mathrm{K}$ & $\begin{array}{l}\text { Black Dia- } \\
\text { mond }\end{array}$ & Soldotna & S & $\mathrm{S}$ & $\mathrm{Y}$ & N/A & $\begin{array}{l}\text {-Compliant label- } \\
\text { package back } \\
\text {-Strawberry flavor } \\
\text { sticker on front side } \\
\text { of package }\end{array}$ \\
\hline $\mathrm{L}$ & $\begin{array}{l}\text { XXX Plati- } \\
\text { num }\end{array}$ & Soldotna & S & S & $\mathrm{Y}$ & JWH-015 (93.2\%) & $\begin{array}{l}\text {-Compliant label- } \\
\text { package back } \\
\text {-Pineapple flavor } \\
\text { sticker on front side } \\
\text { of package }\end{array}$ \\
\hline M & Magic Silver & Wasilla & $\mathrm{L}$ & $\mathrm{S}$ & Y & JWH-398 (79.0\%); JWH-018 (98.4\%) & \\
\hline $\mathrm{N}$ & D.O.A. & Wasilla & $\mathrm{L}$ & $\mathrm{U}$ & $\mathrm{Y}$ & $\begin{array}{l}\text { JWH-081 (98.4\%); JWH-018 (98.4\%) } \\
\text { JWH-203 (39.8\%); JWH-250 (57.4\%) }\end{array}$ & $\begin{array}{l}\text {-Stickers front and } \\
\text { back labels } \\
\text {-Herbal matter be- } \\
\text { tween the sticker and } \\
\text { package }\end{array}$ \\
\hline $\mathrm{O}$ & $\begin{array}{l}\text { Fear and } \\
\text { Loathing }\end{array}$ & Wasilla & $\mathrm{L}$ & $\mathrm{S}$ & Y & JWH-018 (96.4\%) & \\
\hline
\end{tabular}

(Table continued on the next page) 


\begin{tabular}{|c|c|c|c|c|c|c|c|}
\hline Sample ID & Brand & $\begin{array}{l}\text { Location of } \\
\text { purchase }\end{array}$ & Package size & Sealed? & $\begin{array}{l}\text { Analyzed by } \\
\text { GC-MS? }\end{array}$ & $\begin{array}{l}\text { Active ingredients (percent database } \\
\text { match) }\end{array}$ & Observations \\
\hline $\mathrm{P}$ & $\begin{array}{l}\text { Fear and } \\
\text { Loathing II }\end{array}$ & Wasilla & $\mathrm{L}$ & $\mathrm{S}$ & $\mathrm{N}$ & N/A & $\begin{array}{l}\text { "1g" written on the } \\
\text { back in marker }\end{array}$ \\
\hline Q & $\begin{array}{l}\text { California } \\
\text { Dreams } \\
\text { Blue color }\end{array}$ & Wasilla & $\mathrm{L}$ & $\mathrm{S}$ & $\mathrm{N}$ & N/A & \\
\hline $\mathrm{R}$ & Armageddon & Wasilla & $\mathrm{L}$ & $\mathrm{U}$ & $\mathrm{N}$ & N/A & $\begin{array}{l}\text {-Slightly blurry } \\
\text { explosion graphic } \\
\text {-" } 3 \mathrm{~g} \text { " sticker placed } \\
\text { over the printed " } 1 \mathrm{~g} \text { " } \\
\text { label }\end{array}$ \\
\hline S & $\begin{array}{l}\text { Get Real } \\
\text { Red color }\end{array}$ & Wasilla & S & S & $\mathrm{N}$ & N/A & \\
\hline $\mathrm{T}$ & $\begin{array}{l}\text { Black Dia- } \\
\text { mond }\end{array}$ & Wasilla & S & $\mathrm{S}$ & $\mathrm{N}$ & N/A & $\begin{array}{l}\text {-“1.5 grams" printed } \\
\text { text is blurry } \\
\text { - Compliant label- } \\
\text { package back } \\
\text {-Strawberry flavor } \\
\text { sticker on front of } \\
\text { package }\end{array}$ \\
\hline $\mathrm{U}$ & $\begin{array}{l}\text { Get Real } \\
\text { Green color }\end{array}$ & Wasilla & S & S & $\mathrm{N}$ & N/A & $\begin{array}{l}\text { - Compliant label- } \\
\text { package back } \\
\text {-Blueberry flavor } \\
\text { sticker on front of } \\
\text { package. }\end{array}$ \\
\hline V & $\begin{array}{l}\text { XXX Plati- } \\
\text { num }\end{array}$ & Wasilla & S & S & $\mathrm{N}$ & N/A & $\begin{array}{l}\text { - Compliant label- } \\
\text { package back } \\
\text {-Pineapple flavor } \\
\text { sticker on front of } \\
\text { package }\end{array}$ \\
\hline W & No Mames & Wasilla & S & S & $\mathrm{N}$ & N/A & $\begin{array}{l}\text { - Compliant label- } \\
\text { package back } \\
\text {-Blueberry flavor } \\
\text { sticker (same one } \\
\text { as on Sample 21) } \\
\text { placed on top of } \\
\text { printed cherry flavor. }\end{array}$ \\
\hline$X$ & Scooby Snax & Wasilla & $\mathrm{L}$ & $\mathrm{U}$ & $\mathrm{Y}$ & N/A & $\begin{array}{l}\text { Compliant label- } \\
\text { ing for Florida law } \\
\text { HP1175 }\end{array}$ \\
\hline $\mathrm{Y}$ & $\mathrm{OMG}$ & Fairbanks & $\mathrm{L}$ & $\mathrm{U}$ & $\mathrm{Y}$ & N/A & $\begin{array}{l}\text { Compliant label- } \\
\text { package back }\end{array}$ \\
\hline
\end{tabular}

Table 1. Packaging observations and list of active ingredients found in each sample. Abbreviations: package size ( $L=$ large, $S=$ small), sealed packages ( $\mathrm{S}=$ sealed, $\mathrm{U}=$ unsealed), analyzed by $\mathrm{GC}-\mathrm{MS}(\mathrm{Y}=\mathrm{yes}, \mathrm{N}=\mathrm{no}$ ).

quadrupole mass spectrometry detector housed in the UAF Chemistry department. $5 \mu 1$ of liquid sample was injected directly into the system for each analysis. The chromatgraphic separation was performed on a $25 \mathrm{~m} \times 0.25 \mathrm{~mm}$ inner diameter $\mathrm{x} 0.25 \mu \mathrm{m}$ capillary column (Agilent Technologies, Santa Clara, CA; lot 122-5532UIINT). The chromatographic conditions were as follows:

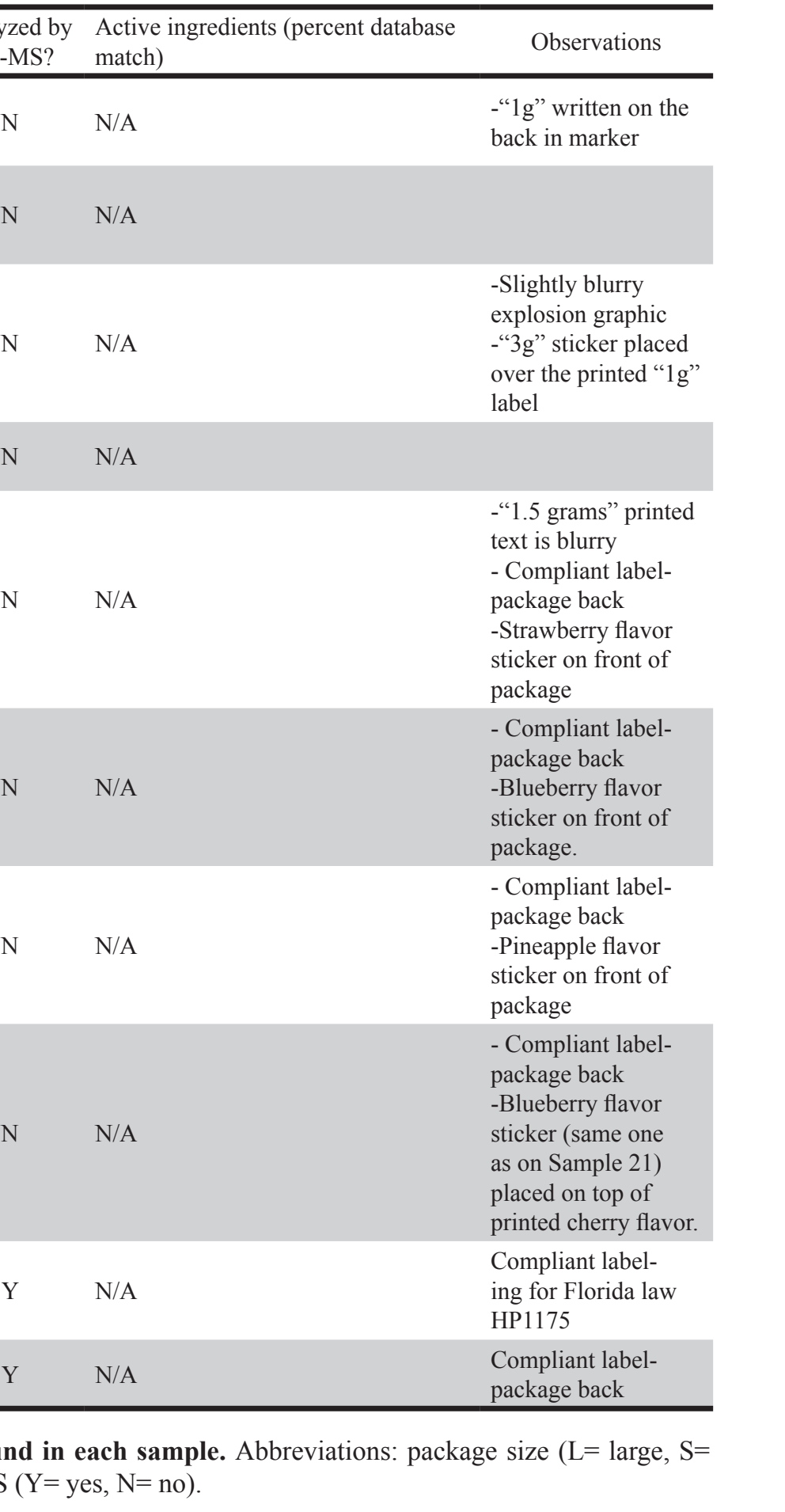

Carrier Gas: Helium at $15 \mathrm{psi}$ - constant pressure

Injection: Splitless for $1.0 \mathrm{~min}$ at $280^{\circ} \mathrm{C}$

Oven: Initial temperature at $150^{\circ} \mathrm{C}$ for $2 \mathrm{~min}$

Ramp $25^{\circ} \mathrm{C} / \mathrm{min}$ to $230^{\circ} \mathrm{C}$

Ramp $5^{\circ} \mathrm{C} / \mathrm{min}$ to $330^{\circ} \mathrm{C}$

Hold for $10 \mathrm{~min}$ 


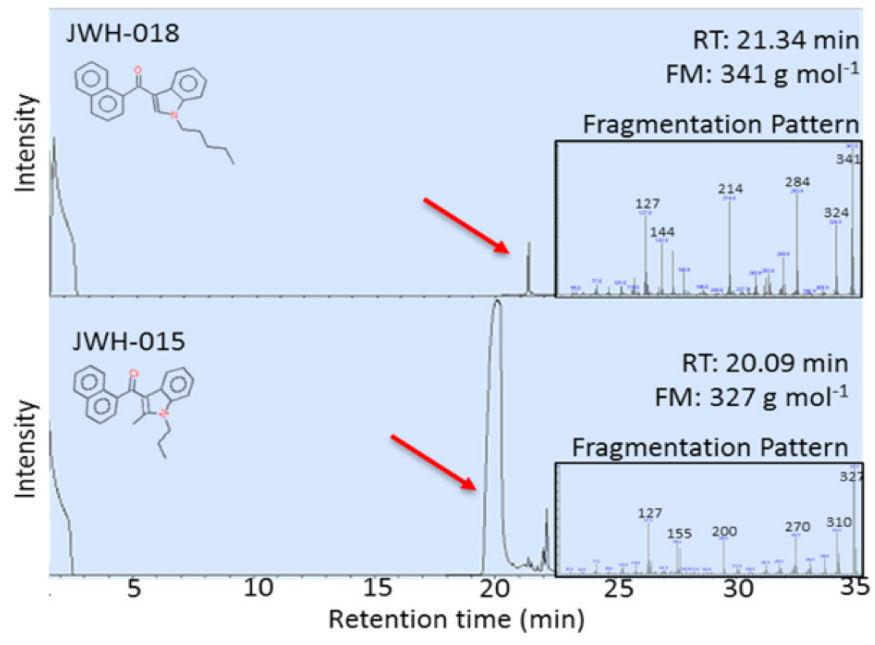

Figure 3. Chromatograms and fragmentation patterns of synthetic cannabinoid standards. Note similar structure of cannabinoid compounds and variable retention time (RT), formula mass (FM), and fragmentation patterns of the cannabinoid standards.

The total ion chromatogram detector acquired data in a full scan mode over a mass range of 50 to $700 \mathrm{Da}$ at a rate of 4 scans/s. Method validation was performed using chemical standards JWH018 (Cerilliant, Round Rock, TX; lot FE121211-04) and JWH-015 (Enzo Life Sciences, Farmingdale, NY, lot 3-H2597E). The standards produced clear peaks, Figure 3, at the appropriate retention times, parent peak and characteristic fragmentation pattern.

\section{RESULTS}

\section{Sample and Packaging Observations}

Packaging of samples obtained from licensed smoke shops were of variable quality. Some samples, such the Get Real (Figure 2 I, J, $\mathrm{S}, \mathrm{U}$ ) and XXX Platinum brands (Figure $2 \mathrm{~L}, \mathrm{~V}$ ), had professionally printed, homogeneous labeling, statements of legal compliance and fully heat-sealed packages. However, other sample packages showed signs of poor quality, which may indicate local or regional production (Figure 4). For example, the graphics printed onto packaging were clear on the Black Diamond and Armageddon packages purchased in Soldotna, and blurry on the packages purchased in Wasilla (Figure 2 D, K, R, T). All samples from Soldotna were heat sealed while a number of packages from Wasilla and Fairbanks were not sealed (Figure 2 N, R, X, Y). The D.O.A. samples had a sticker label adhered to a blank package (Figure 2 $\mathrm{B}, \mathrm{N}$ ), and traces of herbal matter were observed on the backside of the sticker (Figure $2 \mathrm{~N}$ and Figure $4 \mathrm{D}$ ). The Magic Silver purchased in Soldotna had a compliance sticker adhered, which could have been applied at any time after manufacture (Figure 5). The herbal composition between the same brands purchased at different locations had visible differences (Figure 2 E, P and Figure 4 E, F). All the smaller packages had compliance statements printed on the back label and had consistent heat seals indicating a higher level manufacturing operation and pointing towards remote production (Figure 2 I, J, K, L, S, T, U, V, W).

\section{Analysis by GC-MS}

Of the 17 samples analyzed by GC-MS, 12 were found to contain illegal cannabinoids regulated at federal and state levels while cannabinoids were not detected in the other five samples (Figure 2 and Table 1). Packages of Spice from the brands Magic Silver, Sora, Get Real, and XXX Platinum collected in Soldotna had compliance statements or stickers on them, but the sample chromatograms revealed non-compliant chemicals in the samples (Figure 2 F, H, J, L, and Figure 5).

The number and identity of active ingredients were variable between brands and, in some cases, between samples of the same brand purchased at different locations. The D.O.A., Magic Silver, and Fear and Loathing samples were purchased from two locations: Wasilla and Soldotna. Representative chromatograms from D.O.A. samples from the two locations are shown in Figure 6 and an example fragmentation pattern is shown in Figure 7. Each chromatogram measured was distinct, indicating that each sample contained a unique combination of synthetic cannabinoids and herbal components. Of these brands, only Fear and Loathing had the same, illegal single active ingredient (JWH-018) in samples from both locations (Figure $2 \mathrm{C}, \mathrm{O}$ ). The homogeneity in active ingredients of Fear and Loathing may indicate that batches of remotely manufactured Spice are either being imported into Alaska or regionally manufactured and distributed. In contrast, the D.O.A. and Magic Silver samples purchased from each location contained different active ingredients (Figure $2 \mathrm{~B}, \mathrm{~F}, \mathrm{M}, \mathrm{N}$ ), which may indicate more local levels of manufacture and distribution.

The most striking differences noted in Spice packages were in D.O.A. samples purchased at different locations. In both cases, the packages had stickers rather than printed labels. Additionally, the package from Wasilla was not heat-sealed and plant matter was found trapped between the sticker and the package (Figure $4 \mathrm{C}$, D). The chromatograms in Figure 6 show that these D.O.A. samples share three synthetic cannabinoids, identified as JWH-250, JWH-081 and JWH-018, but the remainder of the chromatograms, representing the active ingredients and methanol-soluble fractions of the herbal substrate, are distinct. The D.O.A. from Wasilla contained four active ingredients while the Soldotna's D.O.A. contained seven active ingredients, five of which were matched to the National Institute of Standards and Technology (2011) library with over $97 \%$ certainty (Table 1 ). The data also demonstrates that both the D.O.A. samples contain the illegal compound JWH-018 based on the fragmentation patterns (Table 1 and Figure 7), and close retention times of $21.77 \mathrm{~min}, 21.72 \mathrm{~min}$ and $21.62 \mathrm{~min}$ for the samples from Wasilla, Soldotna and JWH-018 standard, respectively. Additionally, the sample from Soldotna contained other regulated compounds: JWH-019, JWH-073, JWH-203 and RCS-04.

Further evidence of local production includes that samples of D.O.A. and Fear and Loathing II purchased from Soldotna (Figure 2 B, E) contain the same seven active ingredients: JWH-203, 
OMG, Fairbanks

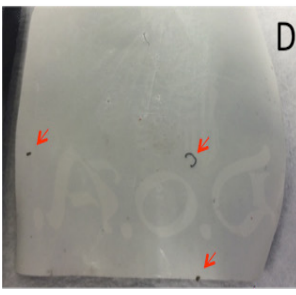

DOA, Wasilla

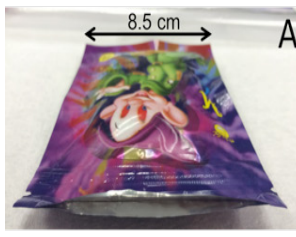

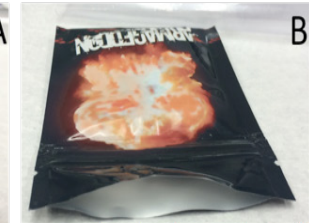

Armageddon, Wasilla
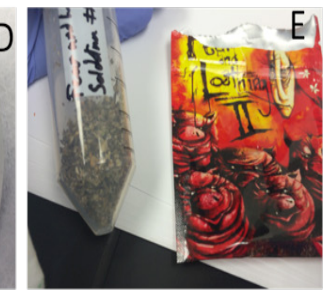

Fear and Loathing II, Soldotna

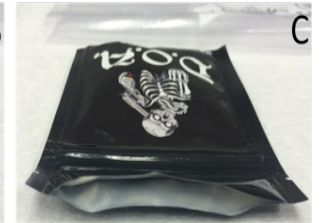

DOA Wasilla

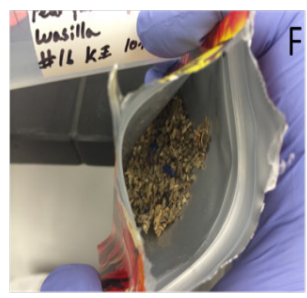

Fear and Loathing II, Wasilla
Figure 4. Discrepancies in packaging and contents of Spice samples. Note the unsealed packages (A, B, and C; each package is $8.5 \mathrm{~cm}$ in width), the label on D.O.A. being a sticker (C and D), the foreign material on the backside of the sticker (D), as well as the difference in herbal substrate's appearance in Fear and Loathing II (E and F). Specifically, (F) contains blue petals and contains larger pieces of herbal substrate, while (E) contains finer pieces of herbal matter and lacks the blue petals.

JWH-250, RCS-04, JWH-073, JWH-018, JWH-019 and JWH-081 as seen in Figure 6. Magic Silver brand Spice was also purchased from both Soldotna and Wasilla. The Soldotna sample of Magic Silver contained three active ingredients while the Wasilla sample of Magic Silver contained two active ingredients. Both samples contained JWH-018, while only the Soldotna sample contained JWH-073 and JWH-250 and only the Wasilla sample contained JWH-398.

Across the 17 Spice samples examined, 12 of them contained at least one synthetic cannabinoid. In total, 10 different synthetic cannabinoids were identified in the samples: JWH-018, RCS-04, JWH-019, JWH-250, JWH-081, JWH-203, JWH-073, JWH-251, JWH-398 and JWH-015 (structures shown in Figure 8). Among these, JWH-018 was the most common, being present in 11 of the 12 illegal samples.

\section{DISCUSSION}

\section{Active Ingredients in Spice}

The chromatograms show potentially illegal cannabinoids present in 12 of the 17 Spice samples analyzed, all of which were purchased legally from licensed smoke shops (Figure 4-7). However, the ingredients listed on the Spice packages include only natural herbs, indicating that the ingredients lists of all samples that contain synthetic cannabinoids are incomplete. Figure 5 shows the presence of JWH-018 in Magic Silver and JWH-015 in XXX Platinum brands despite both being labeled as compliant, which means that they should not contain those regulated compounds. This suggests that manufacturers are willing to feign compliance with federal and state laws in order to sell their products. This practice is in keeping with using the packages labeled "not for human consump- tion" as has been previously reported and also observed in these samples (Yujin et al., 2013). The presence of JWH-018 in 11 of the 17 analyzed samples, showing the widespread use of JWH-018, may be due to its simpler synthesis compared to other cannabinoids rather than being indicative of the manufacturing process (Wang \& Huffman, 2010).

The lack of regulation at the time of sample purchase allowed the distribution of packages of Spice, which have compliance labels, yet without any regulation or quality assurance. This, and the lack of accurate ingredient lists on packaging, complicate the identification of packages that contain illegal cannabinoids, both for law enforcement and consumers. Introducing regulations requiring an independent quality assurance process for each batch of Spice from a manufacturer before reaching distributors to ensure that the compliance labeling is accurate is impractical for Spice, as it is marketed as "not for human consumption" (Hudson \& Ramsey, 2011). Under AK Stat $\S 17.21 .010$, this intermediary process is not necessary because it targets the packaging and appearance of the Spice instead of its chemical composition. However, this legislation seems to be more effective than regulating individual cannabinoids in preventing smoke shops from selling synthetic cannabinoid-containing Spice (Springer et al., 2016).

Local Manufacturing versus Large-Scale Remote Production The results indicate that both larger-scale and small-scale manufacturing of Spice is likely to be carried out within Alaska. Indicators of small-scale production include poor uniformity in packaging as well as the chemical composition of active and inactive ingredients within some brands of Spice purchased from different geographic locations, especially D.O.A. and Magic Silver. However, larger-scale, remote manufacturing is more likely in the case of other brands, such as Fear and Loathing, which appear more professionally prepared and have more consistent active ingredient profiles from both locations.

The poor uniformity in packaging points to a smaller manufacturing process instead of a larger-scale, more automated process. Packaging indicators of local or in-house manufacturing included weak or unsealed heat seals on packages, blurry labels, incorporating stickers into packaging and visible differences in herbal substrates. Another indicator of small-scale production is the large variation of active ingredients and methanol-soluble herbal substrate within the same brand from different geographical locations. The same mixture of cannabinoids identified in the D.O.A. and Fear and Loathing II brands of Spice purchased in Soldotna indicates a local manufacturing process. Figure 6 shows the chromatograms of D.O.A. and Fear and Loathing II, both purchased from Soldotna. Both samples contained the same seven active ingredients. This suggests that these two samples were produced locally and originate from the same batch of Spice.

Other brands of Spice exhibited better quality seals and the visibly crisp labels were printed directly onto the packages. These packages contained fewer active ingredients ( 1 or 0 ) although not all could be analyzed by GC-MS. The brand Fear and Loathing contained the same active ingredient at both locations that the 


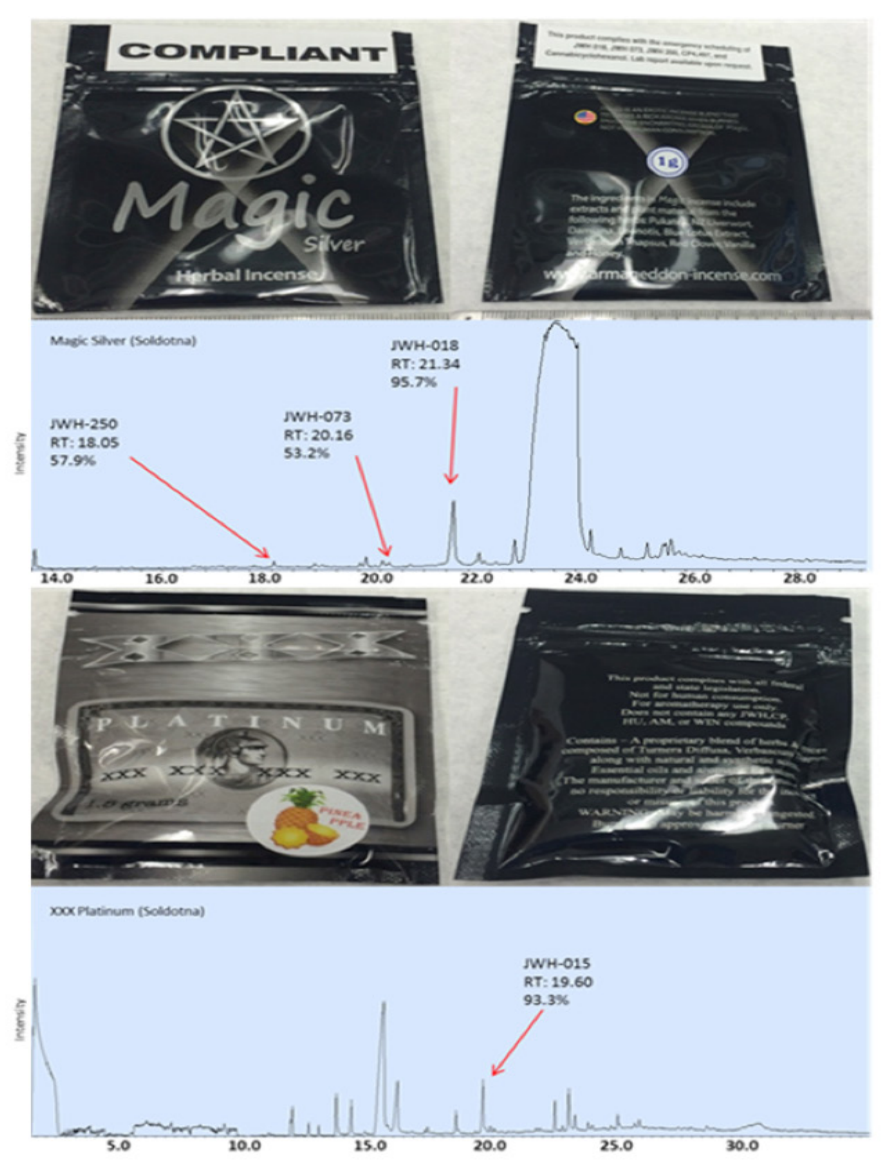

Figure 5. Chromatograms of packages of Spice that are labeled "compliant". Note that the label for "Magic" states the package of Spice does not contain JWH-018, but the GC-MS test revealed a 95.7\% match for JWH-018. The print on "Platinum" states the package of Spice does not contain any JWH compounds, however the GC-MS test revealed a 93.3\% match for JWH-015.

samples were purchased. These observations may point towards a more professional level of production, which is larger in scale and has wider distribution.

\section{Limitations of the Study and Future Directions}

The primary limitation of this study is a small sample size, only 25 samples were collected from three smoke shops and, of those, only 17 samples were analyzed by GC-MS to identify active ingredients. The scope of this study was largely curtailed by the passage of state legislation requiring that all samples be surrendered to law enforcement during the study (AK Stat $\S 17.21 .010,2014$ ), which prevented acquiring additional samples, completing analysis of all samples by GC-MS and the application of liquid chromatographymass spectrometry (LC-MS), which has been previously used to confirm the presence of cannabinoids (Hudson \& Ramsey, 2011). This study establishes the potential utility of a larger scale study with larger number of locations and samples, and the use of multiple techniques to examine the active and inactive ingredients in
Spice to investigate its manufacturing mechanisms in Alaska.

\section{CONCLUSION}

Recent legislative efforts have focused on regulating packaging, which has effectively reduced the distribution of Spice through legal avenues, but has not eradicated the widespread presence and use of the drug in Alaska. Therefore, this research on the manufacture and distribution mechanisms continues to be valuable to law enforcement agencies. GC-MS analysis revealed that Spice packaging does not contain complete ingredient lists, as synthetic cannabinoids were found but not listed. Many of the Spice packages that are labeled as compliant with regulations still contained scheduled cannabinoids. Along with this, GC-MS revealed that samples of Spice often contain multiple active ingredients. The results of this study point to both local and large-scale manufacturing of different Spice brands. The inconsistencies between packaging, lack of seals, same active ingredients between different brands at the same store and differences in the active ingredients in the same brand of Spice that was purchased at different geographical locations point to in-house or local production. However, GC-MS testing revealed that Fear and Loathing did have the same active ingredients from multiple geographical locations, some packages of Spice are professionally sealed and contained fewer synthetic cannabinoids; this could point towards remote production. These results may inform law enforcement's decisions in resource allocation in the efforts to limit Spice use in Alaska.

\section{ACKNOWLEDGEMENTS}

The authors gratefully acknowledge instrument use and support from the University of Alaska Fairbanks (UAF) Department of Chemistry and Biochemistry, Honors Program and Police Department, particularly Honors Director Dr. Marsha Sousa, Lieutenant Barth and Deputy Chief Goetz. This work was supported by grants from UAF's Undergraduate Research \& Scholarly Activity (URSA) and Biomedical Learning and Student Training (BLaST). Work reported in this publication was supported by the National Institute of General Medical Sciences of the National Institutes of Health under three linked awards number RL5GM118990, TL4 GM 118992 and 1UL1GM118991. The work is solely the responsibility of the authors and does not necessarily represent the official view of the National Institutes of Health.

\section{REFERENCES}

Alaska Statutes $\S 17.21 .010$ (2014). Illicit synthetic drugs. Re trieved from: http:// law.justia.com/codes/alaska/2014/title-17/chapter-17.21/section-17.21.010

Alaska Department of Transportation. (2012). Certified Public Road Mileage in Centerline Miles. Retrieved from: http://www.dot.alaska.gov/stwdplng/transdata/pub/2012cprmFinal.pdf

Andrews, L. (2015, September 28). Spice emergency calls in Anchorage rise to new high in October. Alaska Dispatch News. Retrieved from https://www. adn.com/anchorage/article/october-busiest-month-spice-medical-emergency-calls-anchorage/2015/11/04/

Auwärter, V., Dresen, S., Weinmann, W., Müller, M., Pütz, M., \& Ferreirós, N. (2009). 'Spice' and other herbal blends: harmless incense or cannabinoid designer drugs? Journal of Mass Spectrometry, 44(5), 832-7. doi:10.1002/ jms. 1558

Booth, A. L., Wooller, M. J., Howe, T., \& Haubenstock, N. (2010). Tracing geo- 


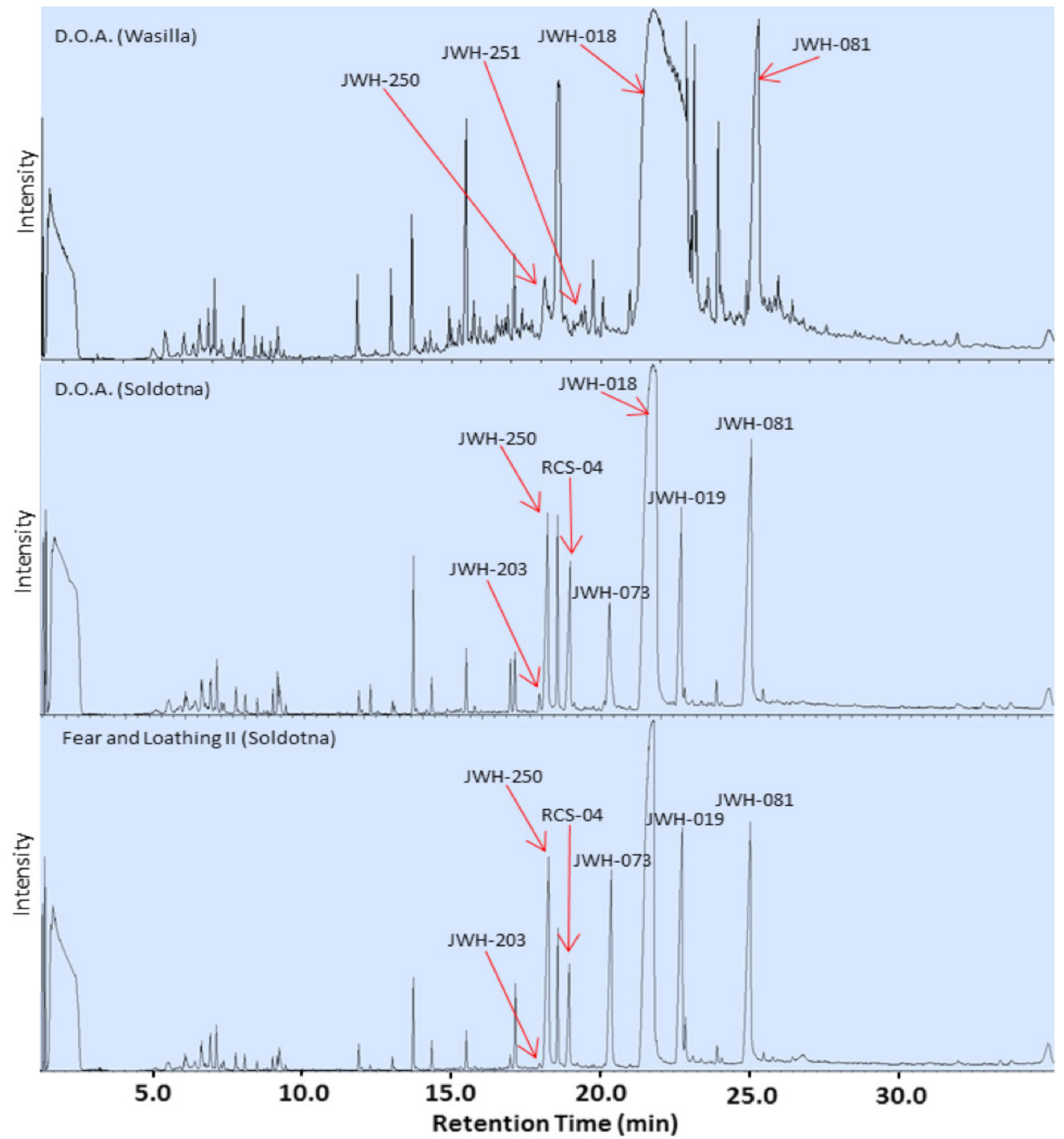

Figure 6. Chromatograms of D.O.A. brand of Spice purchased from different locations and Fear and Loathing II. Note the difference in the number and specific active ingredients present in the same brand purchased from different locations, and the similarity of active ingredients present in two different brands purchased from the same location. 


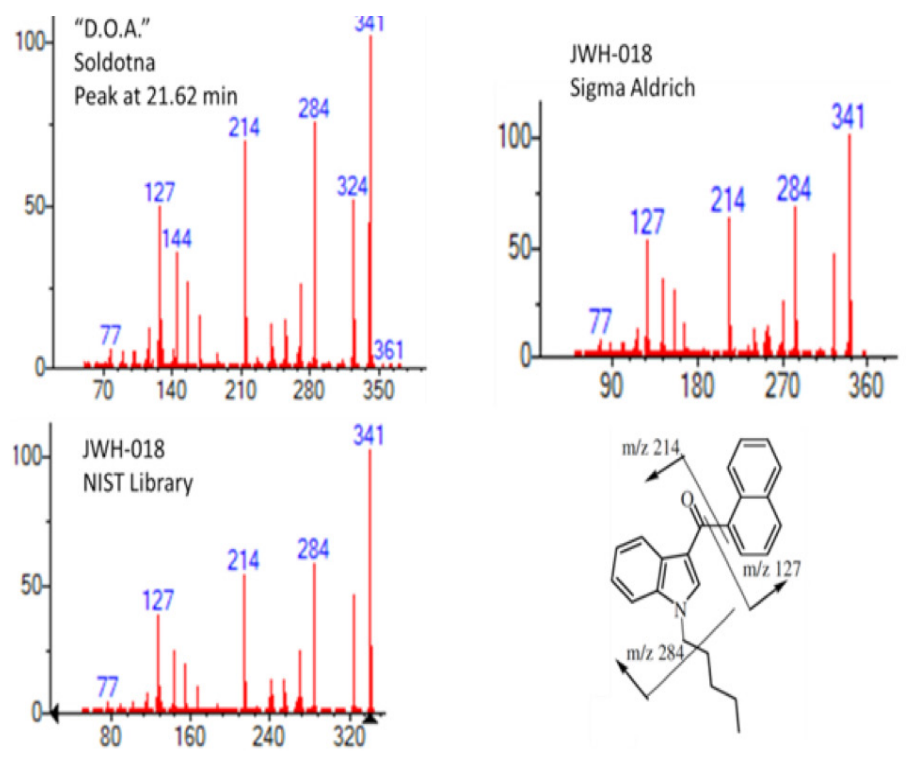

Figure 7. Fragmentation patterns showing suspected active ingredients of Spice samples. Note the similar peaks of the sample compared to the cannabinoid standard and NIST fragmentation pattern library. Molecular fragmentation from Hudson and Ramsey (2011).

graphic and temporal trafficking patterns for marijuana in Alaska using stable isotopes (C, N, O and H). Forensic Science International, 202(1-3), 45-53. doi: 10.1016/j.forsciint.2010.04.025

Carroll, F. I., Lewin, A. H., Mascarella, S. W., Seltzman, H. H., Reddy, P. A., \& Ann, N. Y. (2012). Designer drugs: a medicinal chemistry perspective. Annals of the New York Academy of Science, 1248, 18-38. doi:10.1111/j.17496632.2011.06199.x

Castellanos, D. \& Gralnik, L. M. (2016). Synthetic cannabinoids 2015: an update for pediatricians in clinical practice. World Journal of Clinical Pediatrics 5(1), 16-24. doi: 10.5409/WJCP.v5.i1.16

Centers for Disease Control and Prevention. (2012). Acute kidney injury associated with synthetic cannabinoid use. Morbidity and Mortality Weekly Report, 62(6), 93-8. Retrieved from https://www.ncbi.nlm.nih.gov/pubmed/23407124

Centers for Disease Control and Prevention. (2013a). Notes from the field: severe illness associated with reported use of synthetic marijuana. Morbidity and Mortality Weekly Report, 62(49), 1016-7. Retrieved from https://www.ncbi. nlm.nih.gov/pubmed/24336136

Centers for Disease Control and Prevention. (2013b). Notes from the field: severe illness associated with synthetic cannabinoid use. Morbidity and Mortality Weekly Report, 62(46), 939. Retrieved from https://www.ncbi.nlm.nih.gov/ pubmed/24257204

Hudson, S. \& Ramsey, J. (2011). The emergence and analysis of synthetic cannabinoids. Drug Testing and Analysis, 3(7-8), 466-78. doi: 10.1002/dta.268

Kasper, A. M., Ridpath, A. D., Arnold, J. K., Chatham-Stephens, K., Morrison, M., Olayinka, O., ... Dobbs T. (2015). Severe Illness Associated with Reported Use of Synthetic Cannabinoids. Morbidity and Mortality Weekly Report, 64(39), 1121-2 doi: 10.15585/mmwr.mm6439a7

Köhling, R. (2011). Synthetic cannabinoids - new standards, methods and suitable sample utilities for forensic toxicology. AnalytiX, 9(4). Retrieved from http:// www.sigmaaldrich.com/technical-documents/articles/analytix/synthetic-cannabinoids.html

Law, R., Schier, J., Martin, C., Chang, A., \& Wolkin, A. (2015). Notes from the field: increase in reported adverse health effects related to synthetic cannabinoid use. Morbidity and Mortality Weekly Report, 64(22), 618-9. Retrieved from https://www.cdc.gov/mmwr/preview/mmwrhtml/mm6422a5.htm

National Institute of Standards and Technology. (2011). NIST Mass Spectral Search Program using MIST/EPA/NIH Mass Spectral Library (Version 2.0 G, Build
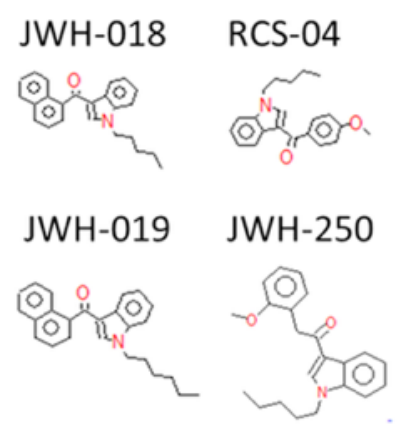

JWH-081 JWH-203
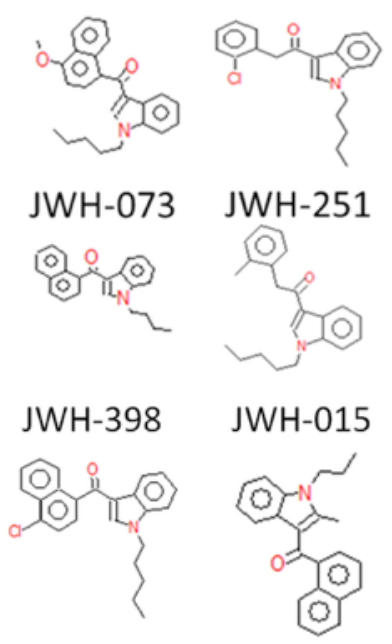

Figure 8. Chemical structures of the synthetic cannabinoids found in Spice samples. Structures obtained from NIST Mass Spectral Library (NIST, 2011).

May 19, 2011). Accessed through Agilent MSD Productivity ChemStation for GC and GC-MS Systems Data Analysis Application.

Ogata, J., Uchiyama, N., Kikura-Hanajiri, R., \& Goda, Y. (2012). DNA sequence analyses of blended herbal products including synthetic cannabinoids as designer drugs. Forensic Science International, 227(1), 33-41. doi: 10.1016/j. forsciint.2012.09.006

Sacco, L. N. \& Finklea, K. (2013). Synthetic drugs: overview and issues for congress. Congressional Research Service, Washington, DC. Retrieved from: https://fas.org/sgp/crs/misc/R42066.pdf

Springer, Y. P., Gerona, R., Scheunemann, E., Schafer, S. L., Lin, T., Banister, S. D., Cooper, M. P., Castrodale, L. J., Levy, M., Butler, J. C., \& McLaughlin, J. B. (2016). Increase in Adverse Reactions Associated with Use of Synthetic Cannabinoids - Anchorage, Alaska, 2015-2016. Morbidity Mortality Weekly Report 2016, 65, 1108-1111. doi: 10.15585/mmwr.mm6540a4

Wang, L. \& Huffman, J. W. (2010). Organic chemist invented a compound in 1995 that is now at the center of a controversy brewing over synthetic marijuana. Chemical \& Engineering News, 88(26), 43. doi: 10.1021/cen-v088n026.p043

Yujin, P., Chul, L., Heesang, L., Jaesung, P., Jiyeong, J., Jaesin, L., Hyeyoung, C., Suncheun, K., Ran, S. H., Yonghoon, P., Bang, Y. H., Sanggil, C., \& Jee, H. J. (2013). Identification of a new synthetic cannabinoid in a herbal mixture: 1-butyl-3-(2-methoxybenzoyl)indole. Forensic Toxicology, 31(2), 187-196. doi: 10.1007/s11419-012-0173-2 